PAPER

\title{
Specific DWI lesion patterns predict prognosis after acute ischaemic stroke within the MCA territory
}

\author{
O Y Bang, P H Lee, K G Heo, U S Joo, S R Yoon, S Y Kim
}

See Editorial Commentary, p 1187

J Neurol Neurosurg Psychiatry 2005;76:1222-1228. doi: 10.1136/jnnp.2004.059998

See end of article for authors' affiliations

.....................

Correspondence to: Dr O Y Bang, Department of Neurology, School of Medicine, Ajou University, Woncheon-dong San 5, Paldal-ku, Suwon,

Kyungki-do, 442-749, South Korea; nmboy@ unitel.co.kr

Received 1 December 2004 Revised version received 26 January 2005 Accepted 27 January 2005
Background: Apart from diffusion-weighted imaging (DWI) lesion volume and diffusion-perfusion mismatching, there is limited information about neuroradiological predictors of early prognosis after an ischaemic stroke. This study sought to identify specific DWI lesion patterns that would help prediction of early prognosis of three different endpoints: unstable hospital course, recurrence of stroke, and poor neurological outcome at 90 days after ischaemic stroke.

Methods: A total of 426 patients with acute cerebral infarcts within the middle cerebral artery territory were prospectively studied. Using the DWI data the patients were divided into six groups (territorial, other cortical, small superficial, internal border zone, small deep, and other deep infarcts), and any recurrent strokes and prognosis over the following 90 days were recorded.

Results: DWI lesion pattern was a stronger and more consistent independent outcome predictor than DWI lesion volume. The specific DWI lesion patterns associated with each endpoint differed. An unstable hospital course was frequently observed in patients with internal border zone infarcts, whereas recurrent strokes after the index stroke were commoner in those who had small superficial infarcts $(p<0.05$ in both cases). Similarly, poor outcome after stroke was associated with older age, severe neurological deficits at admission, and a DWI lesion pattern showing internal border zone infarcts.

Conclusions: The results of the present study indicate that the DWI lesion pattern may help in recognition of the likely differences in the early prognostic endpoints after ischaemic stroke, and DWI analysis may guide targeted interventions to prevent negative outcomes.
$\mathrm{T}$ here has been considerable interest in diffusion-weighted imaging (DWI) as a possible surrogate outcome marker after ischaemic stroke. Several studies have suggested that DWI lesion volume predicts outcome: the larger the visible lesion on DWI, the worse the outcome. ${ }^{1-7}$ Most studies have been small, and generally they did not test for independent associations of imaging variables with outcome. Moreover, most studies have focused on only one of many possible endpoints (that is, recurrence of stroke or poor neurological outcome). However in this respect, a more comprehensive evaluation is needed.

Besides ischaemic volume and diffusion-perfusion mismatching, information about neuroradiological predictors of early prognosis after ischaemic stroke is limited. It has been reported that the pattern of the lesions identified on DWI is correlated with the pathogenic mechanisms underlying the stroke. $^{8-10}$ Moreover, decision making based on DWI lesion patterns has many advantages, particularly in the acute phase of ischaemic stroke, in that it is a simpler and less time consuming procedure than volume analysis of DWI lesions.

Therefore, we prospectively investigated the independent predictors of prognosis of stroke, especially DWI lesion variables (including the volume and pattern), in a large number of patients with varying severity of clinical stroke, taking into account potentially confounding variables. Our study sought to identify specific DWI lesion patterns useful in the prediction of early prognosis of three different endpoints, namely unstable hospital course, recurrence of stroke, and neurological outcome at 90 days after an ischaemic stroke.

\section{METHODS}

\section{Patient selection}

Between July 2000 and October 2003, we prospectively studied consecutive patients with acute symptomatic middle cerebral artery (MCA) territory infarcts, who were admitted to the Department of Neurology at Ajou University Hospital. The patients included in the study were those who had experienced focal symptoms, had been observed within seven days of symptom onset, had been followed for more than 90 days, and who showed relevant lesions within the MCA distribution territory on DWI (fig 1). Patients treated with thrombolysis were excluded. Of 1108 patients with stroke who were admitted during the study period, 426 patients (248 men (58\%), 178 women (42\%); mean (SD) age 61.0 (12.7) years, range 32-90) were included in the study (fig 1 ).

All the patients gave their consent to participate in the study.

\section{Work-up}

We evaluated the patients according to a protocol that included demographic data, medical history, vascular risk factors, and scores on stroke scales (the National Institutes of Health Stroke Scale (NIHSS), the Barthel index (BI), and the modified Rankin Scale (mRS)), as in our previous study. ${ }^{11} \mathrm{~A}$ $1.5 \mathrm{~T}$ clinical MR system was used for both T2-weighted imaging and DWI in all patients. Most of the patients (98.1\%) underwent diagnostic testing, including digital subtraction or magnetic resonance angiography, echocardiograms, electrocardiograms, and routine blood tests. The degree of stenosis was measured as has been reported previously, ${ }^{11}$ and occlusive lesions were defined as stenosis of greater than $50 \%$ or occlusion of the large intracranial vessels and internal carotid artery.

Abbreviations: $\mathrm{BI}$, Barthel index; $\mathrm{DWI}$, diffusion-weighted imaging; MCA, middle cerebral artery; mRS, modified Rankin Scale; NIHSS, National Institutes of Health Stroke Scale 
1108 patients with acute ischaemic stroke/TIA admitted during study period (July 2000-October 2003)
Figure 1 Selection of patients. DWI, diffusion-weighted imaging; MCA, middle cerebral artery; TIA, transient ischaemic attack.

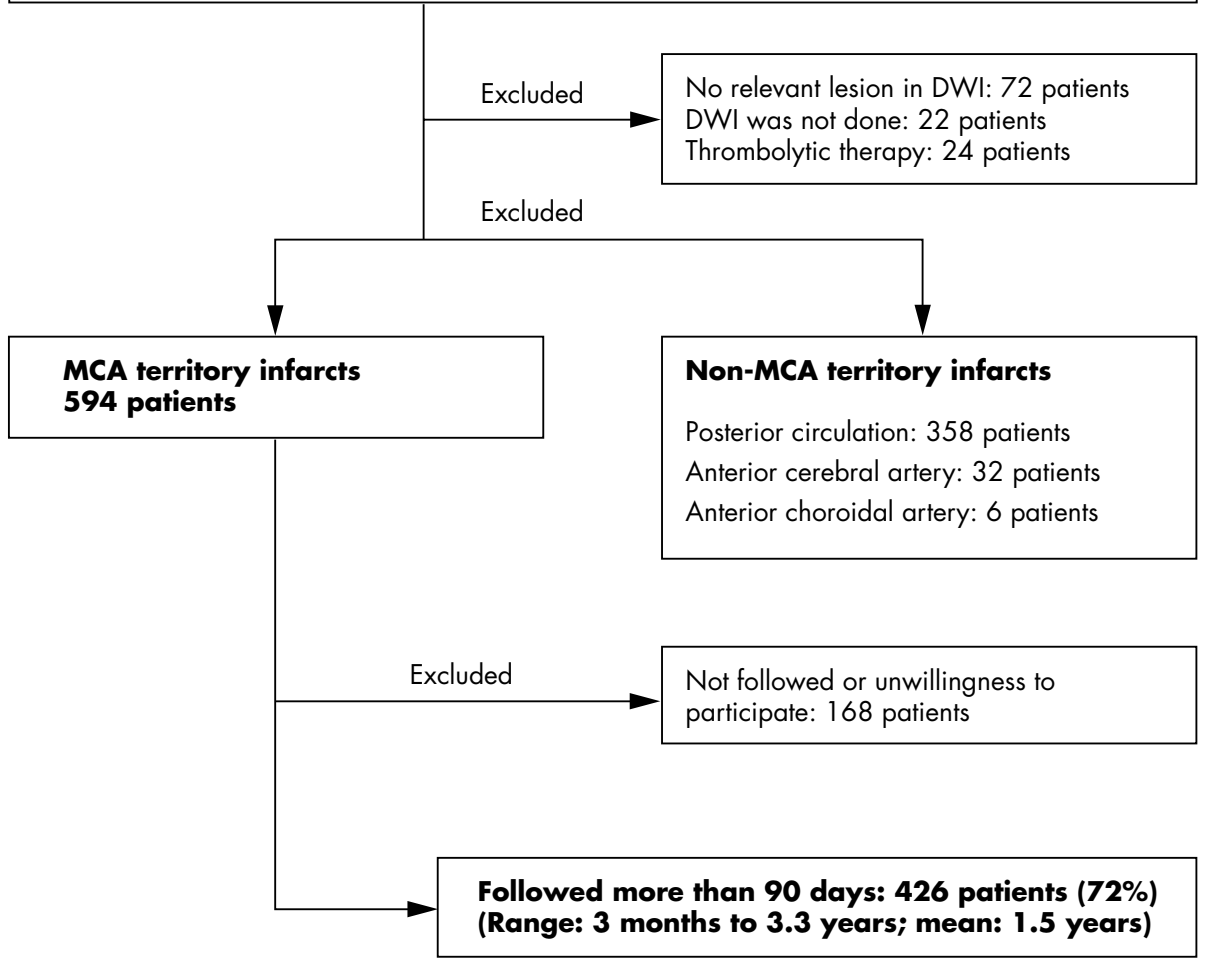

In addition, follow up axial DWI and T2-weighted imaging were done $72-96$ hours after the initial DWI in selected patients who had a stable hospital course and had been enrolled between July and October 2003.

\section{DWI lesion patterns}

We divided the patients into six groups based on the observed DWI patterns (fig 2):

- territorial infarcts involving two or more subdivisions

- other cortical infarcts-that is, cortical infarcts involving one subdivision or cortical border zone

- small superficial infarcts-that is, multiple small cortical infarcts, or single or multiple superficial infarcts in the centrum ovale

- internal border zone infarcts

- small deep infarcts

- other deep infarcts-that is, large striatocapsular lesions (DWI lesion size $>15 \mathrm{~mm}$ ), or concomitant DWI lesions outside the striatocapsular area.

The MCA territory was divided into three subdivisions, deep, superior, or inferior, according to the template reported previously. ${ }^{12}$ Multiple small superficial infarcts were defined as small, multifocal ischaemic lesions of $<1 \mathrm{~cm}$ in diameter, involving the cortex or centrum ovale on $\mathrm{DWI}^{13}$; internal border zone infarcts were defined as multilocular chain-like lesions, confluent striated lesion patterns, or solitary lesions located in the supraventricular or paraventricular areas. ${ }^{14}$

Two readers (KGH and USJ) blinded to the clinical data analysed the DWI data; interobserver agreement was $91 \%$ for the interpretation of DWI lesion patterns. A third reader's (SRY) opinion was obtained in cases of disagreement. We also measured the volumes of the DWI lesion(s) in all patients; the volumes were computed by multiplying the measured area per slice by the section thickness (TR, 10000 ms; TE, $104 \mathrm{~ms}$; slice thickness $7 \mathrm{~mm}$; no gap).

\section{Clinical outcome}

The three different endpoints evaluated were: unstable hospital course; recurrence of stroke; and poor neurological outcome at 90 days after ischaemic stroke. The NIHSS score was serially checked at $1,3,5$, and 7 days after admission. The hospital course was determined on the seventh day after admission and defined as follows: improved (when the NIHSS score decreased by $\geqslant 2$ points); stable (when the score decreased by $<2$ points); worsening (when the score increased after admission); fluctuating (when the score episodically increased and then decreased or vice versa). We also evaluated the level of deterioration and defined marked deterioration as an increase in NIHSS $\geqslant 4$ points during the first seven days of hospitalisation.

The patients were evaluated at three month intervals by one of the authors at the outpatient clinic. We defined recurrent stroke as a focal neurological deficit occurring suddenly in a vascular territory, lasting more than 24 hours, and occurring at any time after the acute phase of the index stroke. To define the outcome of the patients with stroke, the patient scores on the BI at 90 days after stroke onset were divided into two classes with a cut-off value of 60; similarly, patient scores on the mRS were divided using a cut-off value of 3 .

\section{Statistical analysis}

We analysed the differences between the groups using the $\chi^{2}$ test, Fisher's exact test, Student's $t$ test, or one way analysis of variance (ANOVA) with post hoc analysis. Kaplan-Meier curves were used to estimate time of survival free of recurrent stroke. Independent association of DWI lesion variables (DWI lesion volume and pattern) with functional outcome was 

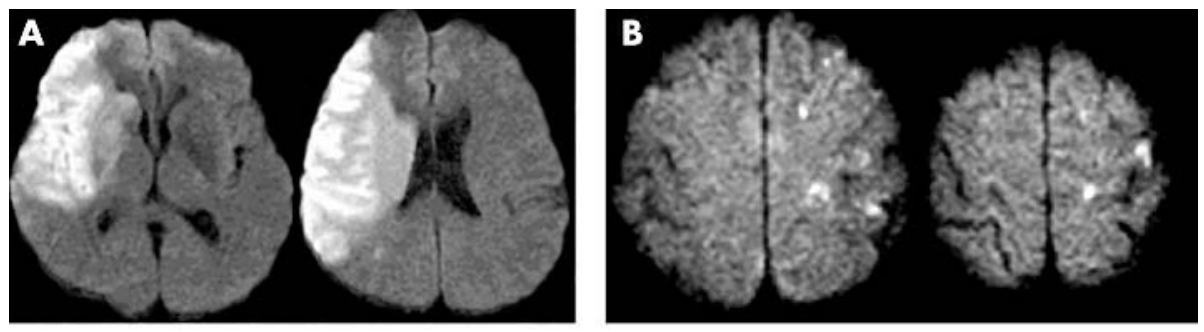

Figure 2 Diffusion-weighted imaging lesion patterns: (A) territorial infarcts, (B) small superficial infarcts, (C) other cortical infarcts, (D) internal border zone infarcts, (E) small deep infarcts, and $(F)$ other deep infarcts.
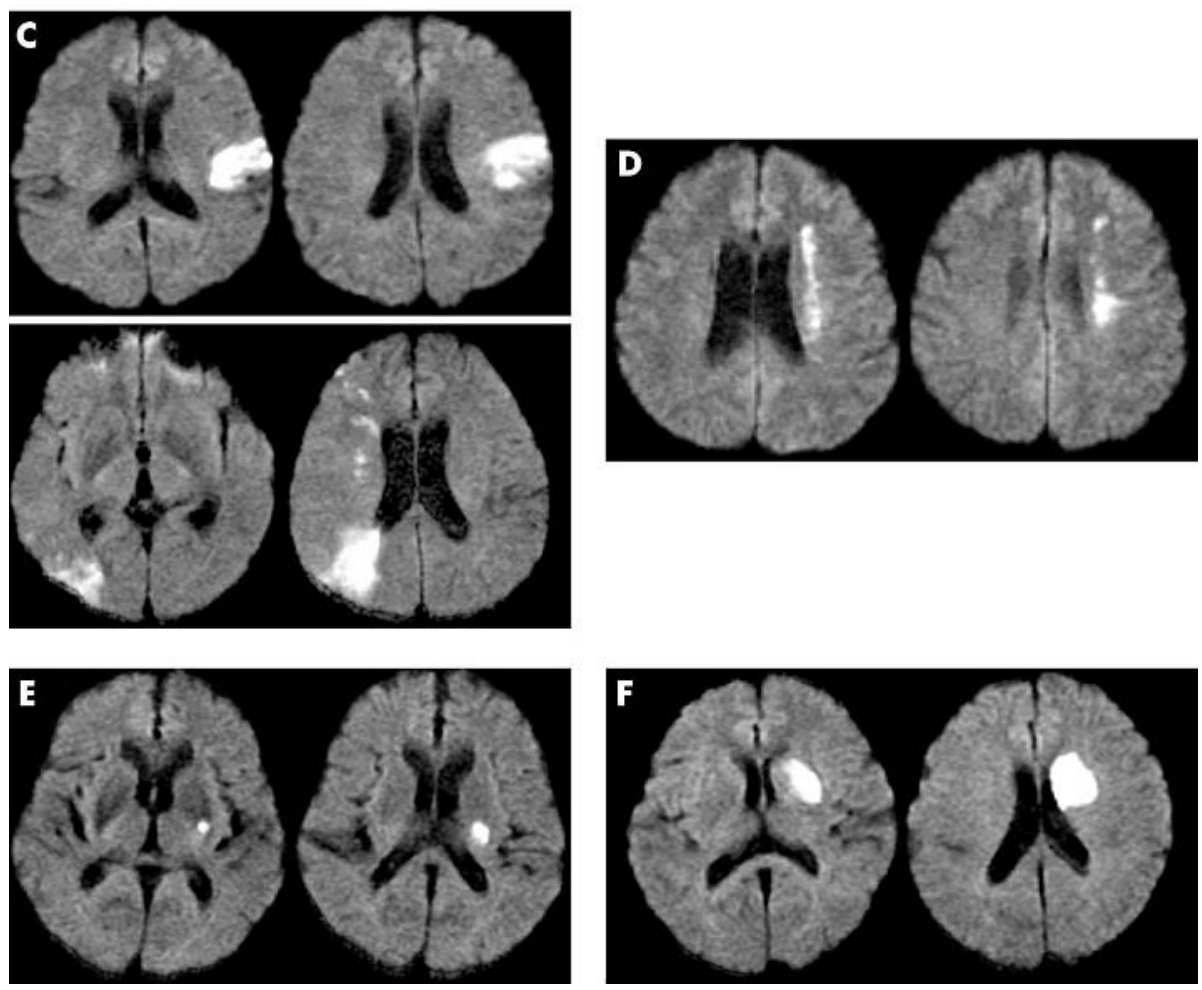

tested as previously reported $^{7}$; we performed a multiple logistic regression analysis to determine whether any imaging variables were independent predictors for each endpoint of the prognosis, over and above the initial clinical severity of the stroke, vascular status, the age and sex of the patient, or the time elapsed from stroke onset and DWI. Those that were significant at the 0.2 level were entered into the initial multivariate model. Once we had obtained the most parsimonious model by backward stepwise elimination of the non-significant factors, each of the excluded variables was again entered separately into the model to test its contribution to the final model. The results are given as odds ratios (OR) estimates of relative risk, with 95\% confidence interval (CI). Statistical significance was established at the $\mathrm{p}<0.05$ level.

\section{RESULTS}

Clinical and radiological characteristics at admission According to the DWI lesion patterns, 48/426 patients were classified as having territorial infarcts, 66 as having other cortical infarcts, 102 as having small superficial infarcts, 31 as having internal border zone infarcts, 137 as having small deep infarcts, and 42 as having other deep infarcts (table 1). The patients' clinical characteristics are shown in table 1 .

The age and sex ratio did not differ between the groups. The NIHSS score at admission was highest to a significant degree in patients with territorial infarcts, and lowest in those with small deep or small superficial infarcts $(p<0.001)$.
Hypertension and diabetes mellitus were less frequently found in patients with territorial infarcts, whereas smoking was more frequently observed in patients with small deep infarcts $(p<0.05)$. The prevalence of atrial fibrillation was highest in patients with territorial infarcts, and occlusive lesions in the relevant vessels in patients with internal border zone infarcts $(p<0.001)$. Previous coronary heart disease was commoner in the patients with cortical infarcts of any type (territorial, other cortical, or small superficial infarcts) than in those with internal border zone and deep (small or other) infarcts $(p<0.05$ in both cases $)$.

All the patients underwent DWI at 38.9 (42.1) hours (range 2-182) after the onset of symptoms (fig 3). The time interval between the onset of symptoms and the time of DWI scanning did not differ between the DWI lesion pattern groups $(p=0.153)$ (table 2$)$. The DWI volume was different between the groups, being higher in territorial infarcts, intermediate in other cortical infarcts, and lower in other groups $(\mathrm{p}<0.001)$.

\section{Unstable hospital course}

Hospital course was determined on the seventh day of hospitalisation in all the patients. The frequencies of both unstable course (worsening and fluctuating) and marked deterioration during the first seven days of hospitalisation differed among the groups $(\mathrm{p}<0.001$ in both cases) (table 2$)$. An unstable hospital course was most frequent in those with internal border zone infarcts (39\%), followed by territorial 
Table 1 Clinical features and risk factors in each diffusion-weighted imaging lesion pattern

\begin{tabular}{|c|c|c|c|c|c|c|}
\hline & Territorial & Other cortical & Small superficial & $\begin{array}{l}\text { Internal border } \\
\text { zone }\end{array}$ & Other deep & Small deep \\
\hline$N(\%)$ & $48(11)$ & $66(16)$ & $102(24)$ & $31(7)$ & $42(10)$ & $137(32)$ \\
\hline Age in years (mean (SD)) & $61.1(14.7)$ & $61.4(15.5)$ & $62.0(12.1)$ & $61.2(15.8)$ & $58.6(10.9)$ & $60.7(11.6)$ \\
\hline Men $(\mathrm{n}(\%))$ & $27(56)$ & $37(56)$ & $61(60)$ & $14(45)$ & $21(50)$ & $88(64)$ \\
\hline NIHSS score on admission* (mean (SD)) & $12.5(5.8)$ & $5.4(5.1)$ & $2.8(4.0)$ & $5.5(5.0)$ & $4.8(5.6)$ & $2.3(2.1)$ \\
\hline \multicolumn{7}{|l|}{ Conventional risk factors (n (\%)) } \\
\hline Hypertension & $15(31)$ & $41(62)$ & $62(61)$ & $18(58)$ & $25(60)$ & $84(61)$ \\
\hline Diabetes & $7(15)$ & $16(24)$ & $25(25)$ & $13(42)$ & $10(24)$ & $38(28)$ \\
\hline Smoking & $19(40)$ & $22(33)$ & $42(41)$ & $9(29)$ & $14(33)$ & $68(50)$ \\
\hline \multicolumn{7}{|l|}{ Serum cholesterol (mean (SD)) } \\
\hline Ratio of total to HDL & $4.2(1.4)$ & $4.3(1.6)$ & $4.5(1.2)$ & $4.7(1.3)$ & $4.6(1.4)$ & $4.6(1.6)$ \\
\hline LDL (mg/dl) & $111.9(34.8)$ & $116.2(36.6)$ & $110.3(39.0)$ & $116.8(37.0)$ & $129.5(36.5)$ & $120.4(40.0)$ \\
\hline Previous stroke history & $9(19)$ & $17(26)$ & $23(23)$ & $3(10)$ & $9(21)$ & $31(23)$ \\
\hline Atrial fibrillation & $14(29)$ & $7(11)$ & $7(7)$ & $2(6)$ & $4(10)$ & $3(2)$ \\
\hline Previous coronary heart disease history† (n (\%)) & $6(13)$ & $6(9)$ & $11(11)$ & 1 (3) & $1(2)$ & $8(6)$ \\
\hline \multicolumn{7}{|c|}{ Vascular status (n (\%)) } \\
\hline Normal & $13(29)$ & $29(45)$ & $22(22)$ & $4(13)$ & $16(38)$ & $102(75)$ \\
\hline Occlusive lesionsł & $32(71)$ & $35(55)$ & 78 (78) & $27(87)$ & $26(62)$ & $34(25)$ \\
\hline Stenosis & $5(11)$ & $21(33)$ & $57(57)$ & $14(45)$ & $15(36)$ & 31 (23) \\
\hline Occlusion & $27(60)$ & $14(22)$ & $21(21)$ & $13(42)$ & $11(26)$ & $3(2)$ \\
\hline
\end{tabular}

infarcts $(27 \%)$, compared with patients with other DWI lesion patterns $(9-21 \%)$. Similarly, marked deterioration was frequently observed in patients with internal border zone infarcts (16\%) and territorial infarcts (13\%).

\section{Recurrence of stroke}

This outcome, as measured with the BI at 90 days after stroke and recurrence of stroke during the follow up period (mean 1.5 years, range, 3 months to 3.3 years) was evaluated in all the patients. As shown in table 2 and fig 4, the recurrence rate of strokes after the index stroke differed depending on the DWI lesion patterns $(p=0.012)$; the recurrence rate was highest in patients with small superficial infarcts $(17 \%)$, followed by internal border zone infarcts (13\%) and other cortical infarcts (13\%). Recurrent stroke occurred less frequently in patients with deep infarcts, whether small $(4 \%)$ or large $(7 \%)$.

\section{Poor outcome}

This outcome, as measured with the BI at 90 days after the stroke, was evaluated with respect to the DWI lesion volume and the DWI lesion pattern of the index stroke. There was an

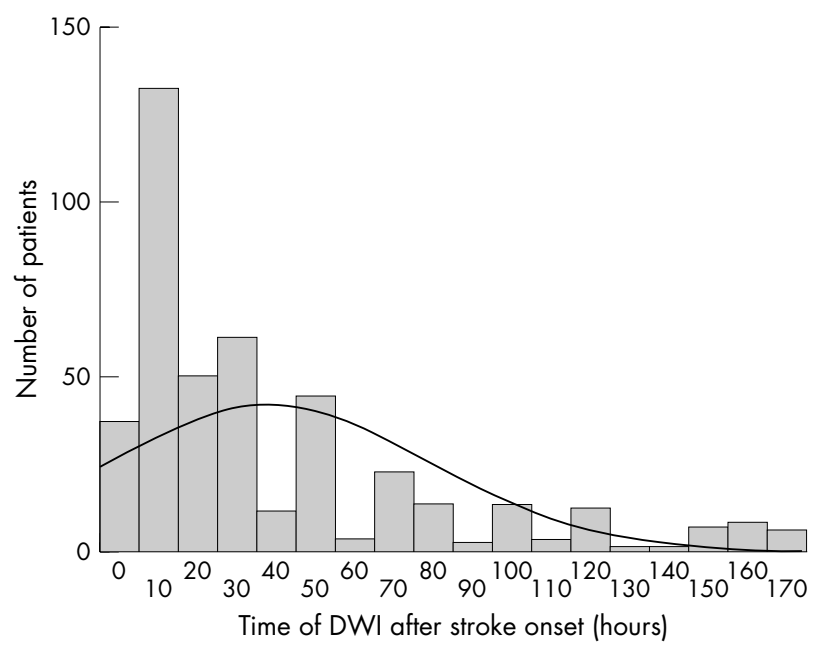

Figure 3 Time of diffusion-weighted imaging (DWI) after the onset of stroke. inverse correlation between the DWI lesion volume and the BI at 90 days after stroke onset $(r=-0.537, \mathrm{p}<0.001)$. However, the association between DWI lesion volume and outcome at 90 days after the stroke was weaker than that between the NIHSS score at admission and the outcome on the 90th day after the stroke $(r=0.761, \mathrm{p}<0.001)$.

The outcome at 90 days after the stroke also differed depending on the DWI lesion pattern (table 2). Although the volume of the DWI lesion was greater in patients with other cortical infarcts $(22.8(36.5) \mathrm{ml})$ than in those with internal border zone infarcts $(11.6(18.3) \mathrm{ml})(\mathrm{p}<0.001)$, patients who showed poor outcome (that is, $\mathrm{BI}<60$ or $\mathrm{mRS}>3$ ) on the 90th day after the stroke were found more frequently in the group with internal border zone infarcts $(42 \%)$ than in the group with other cortical infarcts $(20 \%)$.

\section{Independent association between the DWI lesion patterns and each prognostic endpoint}

Table 3 shows the results of the multiple logistic regression model and ORs for each of the factors. DWI lesion patterns, but not DWI lesion volume, were independently associated with each prognostic endpoint, and the significant factors in the model differed for the three prognostic endpoints. Firstly, the NIHSS score and the DWI lesion pattern of internal border zone infarcts were associated with unstable hospital course and a poor outcome at 90 days after the stroke; patients who had internal border zone infarcts on DWI were about four times more likely to have an unstable course during the early hospitalisation period and about nine times more likely to remain in a severely disabled state at 90 days after the stroke than patients with small deep infarcts on DWI, after adjustment for other factors. Secondly, recurrent stroke was not associated with the severity of the initial neurological deficit or DWI lesion volume, but was associated with the DWI lesion pattern of small superficial infarcts. Patients with such a DWI lesion pattern were about three times more likely to have recurrent strokes after the index stroke than patients with small deep infarcts on DWI, after adjustment for other factors.

\section{Changes in DWI lesion volume and pattern}

In 33 patients, a follow up DWI (time of imaging, 98.6 (10.7) hours after onset of symptoms) was evaluated at 
Table 2 Three different prognostic endpoints after ischaemic stroke for each diffusion-weighted imaging DWI lesion pattern

\begin{tabular}{|c|c|c|c|c|c|c|}
\hline & Territorial & Other cortical & $\begin{array}{l}\text { Small } \\
\text { superficial }\end{array}$ & $\begin{array}{l}\text { Internal border } \\
\text { zone }\end{array}$ & Other deep & Small deep \\
\hline DWI lesion volume in $\mathrm{ml}$ (mean (SD)) & $128.1(71.3)$ & $22.8(36.5)$ & $1.3(3.2)$ & $11.6(18.3)$ & $9.7(16.7)$ & $0.3(0.8)$ \\
\hline $\begin{array}{l}\text { Time from symptom onset to DWI scanning in hours } \\
\text { (mean (SD)) }\end{array}$ & $30.5(49.6)$ & $41.3(46.7)$ & $39.5(45.5)$ & $43.8(44.1)$ & $43.4(42.6)$ & $37.8(35.8)$ \\
\hline \multicolumn{7}{|l|}{ Hospital course (n (\%)) } \\
\hline Unstable course & $13(27)$ & $6(9)$ & $13(13)$ & 12 (39) & $9(21)$ & $15(11)$ \\
\hline Marked deterioration & $6(13)$ & $4(6)$ & $2(2)$ & $5(16)$ & $2(5)$ & $1(1)$ \\
\hline Stroke recurrence $(\mathrm{n})$ & 40 & 64 & 101 & 30 & 41 & 137 \\
\hline Recurrence rate (n (\%)) & $4(10)$ & $8(13)$ & $17(17)$ & $4(13)$ & $3(7)$ & $5(4)$ \\
\hline \multicolumn{7}{|l|}{ Outcome at 90 th day } \\
\hline Barthel index* (mean (SD)) & $41.7(39.2)$ & $79.2(31.1)$ & $92.3(18.6)$ & $68.6(31.8)$ & $80.6(35.0)$ & $94.2(11.9)$ \\
\hline Modified Rankin score† (mean (SD)) & $3.6(1.9)$ & $1.9(1.5)$ & $1.0(1.2)$ & $2.4(1.7)$ & $1.4(1.7)$ & $1.0(1.0)$ \\
\hline Poor outcome $\ddagger$ (mean (SD)) & $30(63)$ & $13(20)$ & $9(9)$ & $13(42)$ & $8(19)$ & $6(4)$ \\
\hline
\end{tabular}

72-96 hours after the initial DWI (14.8 (8.5) hours after onset of symptoms). Changes in the DWI lesion volume were varied (mean $158.0 \%$ (85.9\%), range $57.9-437.5 \%$, compared with the initial DWI lesion volume), and were significantly different between patients with internal border zone infarcts on DWI (six patients, $225.6 \%$ (127.1\%) and those with other patterns (27 patients, $142.9 \%(68.5 \%)(p=0.031)$. However, there were fewer changes in pattern of the DWI lesion on the follow up DWI than in the DWI lesion volume; only three patients (concordance rate $90.9 \%$ ) showed a different DWI lesion pattern compared with the initial DWI lesion pattern. These changes were: other cortical to territorial infarcts $(\mathrm{n}=1)$, small superficial to internal border zone infarcts $(n=1)$, and small deep to other deep infarcts $(n=1)$.

\section{DISCUSSION}

Among the variables measured by DWI, DWI lesion volume has been the most extensively studied. However, in most studies an independent association of DWI lesion volume

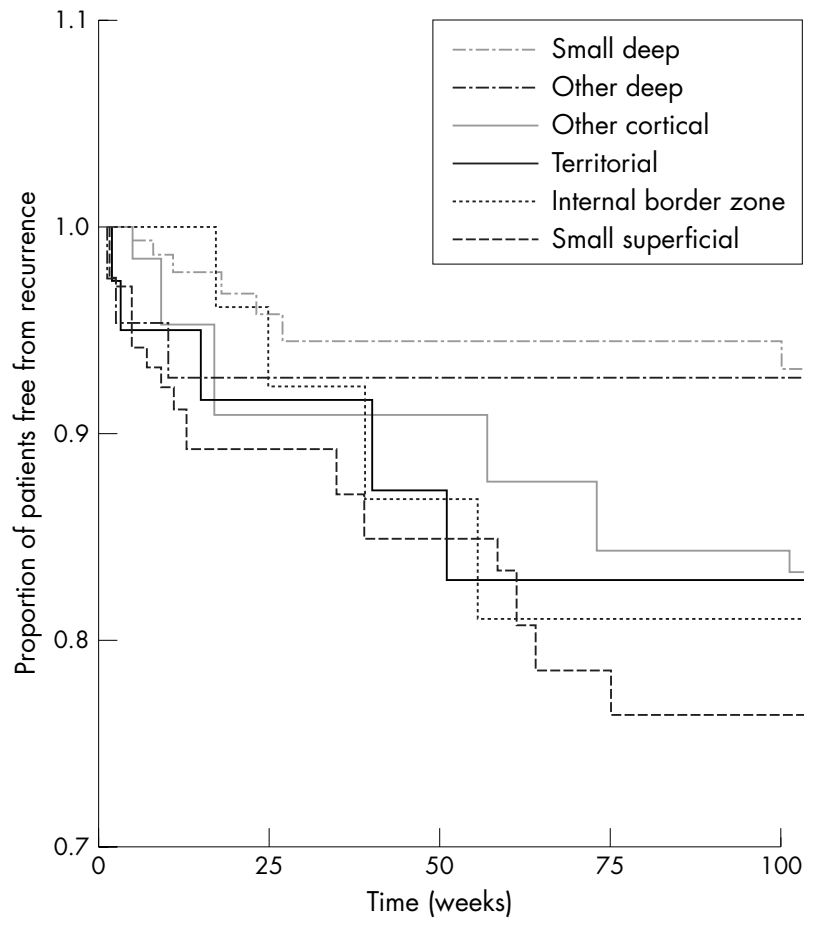

Figure 4 Kaplan-Meier's curves for patients who did not have a recurrent stroke. with functional outcome was not tested,,$^{1-4} 15$ and there have been conflicting results concerning whether the DWI lesion volume is an independent outcome predictor, ${ }^{56}$ or not. ${ }^{7} \mathrm{~A}$ possible explanation for this controversy is that clinical severity is so strongly related to outcome that any other outcome predictors would have to be very strong indeed to achieve independence.

Our results showed that the association between DWI lesion volume and the outcome at 90 days after a stroke was weaker than that between the NIHSS score at admission and the outcome at 90 days after a stroke. Therefore, a DWI variable that can serve as a more potent prognostic predictor than the DWI lesion volume is required. Another explanation for the controversy is that lesions that are imaged within the first 12 hours after onset of symptoms show a significant increase in DWI lesion volume on follow up images, ${ }^{215} 16$ as areas surrounding the core of the lesion become infarcted after the initial MRI was done. ${ }^{17}$ For this reason, in one recent study, time from onset of symptoms to MRI scanning was an independent predictive factor of outcome in the analysis (the longer the time, the better the outcome). ${ }^{5}$ Yet again, one concludes that a more consistent prognostic predictor than the DWI lesion volume is needed. In our present study, the DWI lesion pattern was a strong independent predictor of outcome, and our results also suggest that the degree of increase in DWI lesion volume differs depending on the DWI lesion pattern; patients with internal border zone infarcts on DWI had poorer prognosis, despite the relatively small volume of their DWI lesions. Analysis of the DWI lesion pattern as a predictor of prognosis may be a simple and reasonable method because $(a)$ it is less time consuming and (b) it may be less critical to consider the time elapsed from onset of symptoms to MRI scanning.

Our present study shows that different clinical and DWI variables are associated with different endpoints of stroke prognosis. One possible explanation is that different mechanisms may be involved with respect to each prognostic endpoint after ischaemic stroke-for example, the extent of ongoing ischaemic injury, as well as its severity, may underlie an unstable hospital course and poor outcome at 90 days; and recurrent thromboembolism, as well as large arterial disease with large areas of haemodynamic compromise, may play a role in recurrent stroke.

Our findings demonstrate, firstly, that an unstable hospital course is independently associated with internal border zone infarcts as well as with the severity of neurological deficits at admission. Therapies for patients with internal border zone infarcts may be different from therapies for those with other DWI patterns. More aggressive interventions may be indicated in these patients, who currently are often treated with little urgency. Further therapeutic trials are needed to 
Table 3 Multiple logistic regression analysis

\begin{tabular}{|c|c|c|c|c|c|c|}
\hline \multirow[b]{2}{*}{ Variables } & \multicolumn{2}{|c|}{ Unstable hospital course } & \multicolumn{2}{|c|}{ Poor outcome at $90^{\text {th }}$ day } & \multicolumn{2}{|l|}{ Recurrent stroke } \\
\hline & OR $(95 \% \mathrm{Cl})$ & $p$ value & OR $(95 \% \mathrm{Cl})$ & $\mathrm{p}$ value & OR $(95 \% \mathrm{Cl})$ & $p$ value \\
\hline Age & N/A & 0.920 & $1.03(1.01$ to 1.06$)$ & 0.016 & N/A & 0.429 \\
\hline Sex & N/A & 0.864 & N/A & 0.311 & N/A & 0.778 \\
\hline The NIHSS score & $1.08(1.02$ to 1.15$)$ & 0.010 & $1.33(1.23$ to 1.45$)$ & $<0.001$ & N/A & 0.815 \\
\hline DWI lesion volumes & N/A & 0.456 & N/A & 0.216 & N/A & 0.163 \\
\hline DWI lesion patterns* & & 0.006 & & 0.007 & & 0.043 \\
\hline Territorial & N/A & 0.879 & N/A & 0.066 & N/A & 0.567 \\
\hline Other cortical & N/A & 0.135 & N/A & 0.344 & N/A & 0.359 \\
\hline Small superficial & N/A & 0.769 & N/A & 0.500 & $2.93(1.20$ to 7.14$)$ & 0.035 \\
\hline Internal border zone & 4.21 (1.64 to 10.81$)$ & 0.003 & 9.11 (2.75 to 30.21$)$ & $<0.001$ & N/A & 0.529 \\
\hline Large deep & N/A & 0.236 & N/A & 0.252 & N/A & 0.474 \\
\hline Vascular statust & & 0.226 & & 0.298 & & 0.677 \\
\hline Stenosis & N/A & 0.427 & N/A & 0.966 & N/A & 0.477 \\
\hline Occlusion & N/A & 0.355 & N/A & 0.189 & N/A & 0.818 \\
\hline Time elapsed from stroke onset and DWI & N/A & 0.062 & N/A & 0.984 & N/A & 0.729 \\
\hline
\end{tabular}

determine whether patients with internal border zone infarcts, who may have a high risk of subsequent worsening and a distinct pathophysiology (unstable cerebral haemodynamics), may benefit from more aggressive interventions (such as antithrombotic therapy or angioplasty/surgery), neuroprotective agents (which can be administered before deterioration), or from interventions that increase collateral blood flow (such as hypertensive therapy). Secondly, the recurrence rate of stroke in our study differed depending on the DWI lesion pattern. Our results showed that clinical and radiological variables for the severity of injury (that is, the NIHSS score and DWI lesion volume) were not associated with the recurrence of stroke. In contrast, there was an association between recurrent stroke and the DWI lesion pattern, with higher rates of subsequent stroke in patients with small superficial infarcts compared with those with other DWI lesion patterns. Our results suggest that patients with small superficial infarcts, either multiple small cortical infarcts or small infarcts of the centrum ovale, have a higher chance of recurrent strokes than those with other DWI lesion patterns. Lastly, the severity of ischaemic injury is an independent predictor of poor outcome.

We found that, in addition to the age of the patients, the NIHSS score and the DWI lesion pattern were independent predictors of outcome. The NIHSS score at admission may represent the severity of ischaemic injury at initial presentation, whereas the DWI lesion pattern of internal border zone infarcts may represent the group of patients who are at high risk of evolving stroke during the first few days after the symptoms. Our present results suggest that patients who have internal border zone infarcts on DWI have poor outcomes despite the relatively small infarct volumes on initial DWI; we found large arterial disease in about $90 \%$ of cases, suggesting larger areas of haemodynamic compromise than were reflected in the DWI lesions in these patients. Therefore, the DWI lesion pattern may provide a tool to identify the groups of patients with ongoing ischaemic injury, and it may support the NIHSS score or DWI lesion volume in predicting the outcome after ischaemic stroke. Recently, we have also demonstrated that the clinical features and DWI lesion patterns are different in atherosclerotic MCA and carotid sinus disease, suggesting different pathogenesis. ${ }^{18}$ Our present data provide novel evidence that DWI lesion patterns are a useful measure for evaluation of early prognosis in patients with cerebral infarcts within the MCA territory. If others replicate these results, decisions about use of targeted interventions for the prevention of each prognostic endpoint after acute ischaemic stroke could be assisted by analysis of the DWI pattern.
Although we have tried to predict the outcome at the acute stage of ischaemic stroke by means of DWI lesion variables, further studies are needed. Firstly, stroke subtypes may influence the DWI lesion patterns as well as the prognosis after ischaemic stroke; we did not study this. ${ }^{18-20}$ Secondly, the combination of DWI analysis and differentiation of the underlying cause of stroke, together with investigations of perfusion defects in the acute phase, may allow further understanding of the various pathophysiological mechanisms underlying neurological worsening, stroke recurrence, and poor outcome. Lastly, the occlusive lesions in the nonrelevant vessels and the pattern of old stroke lesions were not evaluated in the present study. Data on these two points could be relevant for evaluating the impact of DWI lesions on stroke outcome.

\section{Authors' affiliations}

O Y Bang, P H Lee, K G Heo, U S Joo, S Y Kim, Department of Neurology and Neuroradiology, School of Medicine, Ajou University, Suwon, South Korea

S R Yoon, Department of Neuroradiology, Shin Hospital, Suwon, South Korea

This work was supported in part by a grant from the Ministry of Health and Welfare (0412-DB00-0101-007) to O Y B.

Competing interests: none declared

\section{REFERENCES}

1 Lovblad KO, Baird AE, Schlaug $G$, et al. Ischemic lesion volumes in acute stroke by diffusion-weighted magnetic resonance imaging correlate with clinical outcome. Ann Neurol 1997;42:164-70.

2 Tong DC, Yenari MA, Albers GW, et al. Correlation of perfusion- and diffusion-weighted MRI with NIHSS score in acute ( $<6.5$ hour) ischemic stroke. Neurology 1998;50:864-70.

3 Barber PA, Darby DG, Desmond PM, et al. Prediction of stroke outcome with echoplanar perfusion- and diffusion-weighted MRI. Neurology 1998;51:418-26.

4 Beaulieu C, de Crespigny A, Tong DC, et al. Longitudinal magnetic resonance imaging study of perfusion and diffusion in stroke: evolution of lesion volume and correlation with clinical outcome. Ann Neurol 1999;46:568-78.

5 Baird AE, Dambrosia J, Janket S, et al. A three-item scale for the early prediction of stroke recovery. Lancet 2001;357:2095-9.

6 Thiis VN, Lansberg MG, Beaulieu C, et al. Is early ischemic lesion volume on diffusion-weighted imaging an independent predictor of stroke outcome? A multivariable analysis. Stroke 2000;31:2597-602.

7 Wardlaw JM, Keir SL, Bastin ME, et al. Is diffusion imaging appearance an independent predictor of outcome after ischemic stroke? Neurology 2002;59:1381-7.

8 Baird AE, Lovblad KO, Schlaug G, et al. Multiple acute stroke syndrome: marker of embolic disease? Neurology 2000;54:674-8.

9 Gandolfo C, Del Sette M, Finocchi C, et al. Internal borderzone infarction in patients with ischemic stroke. Cerebrovasc Dis 1998;8:255-8.

10 Lee PH, Bang OY, Oh SH, et al. Subcortical white matter infarcts: comparison of superficial perforating artery and internal border-zone infarcts using diffusion-weighted magnetic resonance imaging. Stroke 2003;34:2630-5. 
11 Bang OY, Lee PH, Joo SY, et al. Frequency and mechanisms of stroke recurrence after cryptogenic stroke. Ann Neurol 2003;54:227-34.

12 Heinsius T, Bogousslavsky J, Van Melle G. Large infarcts in the middle cerebral artery territory. Etiology and outcome patterns. Neurology 1998:50:341-50.

13 Kimura K, Minematsu K, Koga M, et al. Microembolic signals and diffusionweighted MR imaging abnormalities in acute ischemic stroke. AJNR Am J Neuroradiol 2001;22:1037-42.

14 Mull M, Schwarz M, Thron A. Cerebral hemispheric low-flow infarcts in arterial occlusive disease. Lesion patterns and angiomorphological conditions. Stroke 1997;28:118-23.

15 van Everdingen KJ, van der Grond J, Kappelle L, et al. Diffusionweighted magnetic resonance imaging in acute stroke. Stroke 1998;29:1783-90.
16 Baird AE, Benfield A, Schlaug G, et al. Enlargement of human cerebral ischemia lesion volumes measured by diffusion-weighted magnetic resonance imaging. Ann Neurol 1997;41:581-9.

17 Garcia JH, Lassen NA, Weiller C, et al. Ischemic stroke and incomplete infarction. Stroke 1996:27:761-5.

18 Lee PH, Oh SH, Bang OY, et al. Infarct patterns in atherosclerotic middle cerebral artery versus internal carotid artery disease. Neurology 2004;62:1291-6.

19 Petty GW, Brown RD Jr, Whisnant JP, et al. Ischemic stroke subtypes: a population-based study of functional outcome, survival, and recurrence. Stroke 2000;31:1062-8.

20 Yamamoto H, Bogousslavsky J, van Melle G. Different predictors of neurological worsening in different causes of stroke. Arch Neurol 1998;55:481-6.

\section{Clinical Evidence - Call for contributors}

Clinical Evidence is a regularly updated evidence-based journal available worldwide both as a paper version and on the internet. Clinical Evidence needs to recruit a number of new contributors. Contributors are healthcare professionals or epidemiologists with experience in evidence-based medicine and the ability to write in a concise and structured way.

Areas for which we are currently seeking authors:

- Child health: nocturnal enuresis

- Eye disorders: bacterial conjunctivitis

- Male health: prostate cancer (metastatic)

- Women's health: pre-menstrual syndrome; pyelonephritis in non-pregnant women However, we are always looking for others, so do not let this list discourage you.

Being a contributor involves:

- Selecting from a validated, screened search (performed by in-house Information Specialists) epidemiologically sound studies for inclusion.

- Documenting your decisions about which studies to include on an inclusion and exclusion form, which we keep on file.

- Writing the text to a highly structured template (about 1500-3000 words), using evidence from the final studies chosen, within 8-10 weeks of receiving the literature search.

- Working with Clinical Evidence editors to ensure that the final text meets epidemiological and style standards.

- Updating the text every six months using any new, sound evidence that becomes available. The Clinical Evidence in-house team will conduct the searches for contributors; your task is simply to filter out high quality studies and incorporate them in the existing text.

- To expand the topic to include a new question about once every 12-18 months.

If you would like to become a contributor for Clinical Evidence or require more information about what this involves please send your contact details and a copy of your CV, clearly stating the clinical area you are interested in, to Klara Brunnhuber (kbrunnhuber@ bmigroup.com).

\section{Call for peer reviewers}

Clinical Evidence also needs to recruit a number of new peer reviewers specifically with an interest in the clinical areas stated above, and also others related to general practice. Peer reviewers are healthcare professionals or epidemiologists with experience in evidence-based medicine. As a peer reviewer you would be asked for your views on the clinical relevance, validity, and accessibility of specific topics within the journal, and their usefulness to the intended audience (international generalists and healthcare professionals, possibly with limited statistical knowledge). Topics are usually 1500-3000 words in length and we would ask you to review between 2-5 topics per year. The peer review process takes place throughout the year, and our turnaround time for each review is ideally 10-14 days.

If you are interested in becoming a peer reviewer for Clinical Evidence, please complete the peer review questionnaire at www.clinicalevidence.com or contact Klara Brunnhuber (kbrunnhuber@bmigroup.com). 